\title{
Vehicle Seat Structure Optimization in Front and Rear Impact
}

\author{
Yali Yang ${ }^{*}, 1$, Hao Chen ${ }^{1}$, Ruoping Zhang ${ }^{1}$, Haining Chen ${ }^{1}$ and Xuhua Qiang ${ }^{2}$ \\ ${ }^{I}$ College of Automotive Engineering, Shanghai University of Engineering Science, Shanghai, 201620, China \\ ${ }^{2}$ Shanghai ShuangJie Technology Co., LTD., Shanghai 201804, China
}

\begin{abstract}
Seat is one of the important parameters for occupant safety during an impact. The occupant injury characteristics are vital for better seat development. For improving occupant safety during impact, the research on the seat structure optimization in front and rear impact was conducted in this paper. Dummy-seat finite element simulation model was established and analyzed by using HyperMesh and LS-DYNA software. The model was verified with test data before further application. Then, the model was simulated to determine its performance on the head, chest and neck injury of the dummy in the frontal and rear impact. The simulation results showed that the original model cannot provide effective protection according to CNCAP regulation. Thus, modification should be carried out. On the basis of previous study, seat side plate, lower bracket under cushion, and back lock member were modified by implementing orthogonal experiment design method to determine the best option. The optimized solution $\mathrm{A}_{4} \mathrm{~B}_{2} \mathrm{C}_{2}$ was gained through range analysis and integrated balance method. After simulation, chest compression reduced $17.21 \%$, 3ms resultant acceleration reduced $21.16 \%$, dummy neck $\mathrm{F}_{\mathrm{X}}$ decreased $15.44 \%, \mathrm{M}_{\mathrm{Z}}$ value decreased 3.13\%, and backrest angle decreased $46.1 \%$. It was indicated that the optimized structure can improve passenger protection. It was illustrated that the model based method combining HyperMesh and LSDYNA was an effective way for seat development and for conducting occupant injury study.
\end{abstract}

Keywords: Front and rear impact, Occupant injuries, Orthogonal optimization, Seat.

\section{INTRODUCTION}

With the development of auto industry, the safety of the car has increasingly become an important research field for modern automobile development design $[1,2]$.

As an important safety component, vehicle seat is a hot spot in the study of automobile safety and it provides a decisive protection for passengers [3]. In 2011, Jin [4] systematically introduced the seat safety performance requirements pointing out that seat back should be strengthened, the cushion stiffness improved and headrest redesigned on low-speed crash protection. Yang [5] analyzed that insufficient stiffness of seat cushion is the cause of human body diving in rear collision which results in greater damage on the abdomen in 2012. According to the recent research status abroad, Nicolas [6] established finite element models of multi-body human body and seat to study the safety of the crew in rear crash. Masahide et al. [7] from Japan's Toyota motor crop studied occupant protection during the car crashes. Chen [8] established multi-rigid-body crash model to analyze the seat parameter effect on passenger injury during rear impact and optimize the seat structure. Wang [9] conducted research study on seat strength and stiffness in front crash and optimized seat to provide better passenger protection.

The seat safety research has laid emphasis on the strength of seat and body connection and seat features during frontal crash, and headrest safety and backrest strength in rear

\footnotetext{
*Address correspondence to this author at the College of Automotive Engineering, Shanghai University of Engineering Science, No. 333 Longteng Road, Shanghai 201620, China; Tel: +86 13585901281; E-mail: carolyn71@163.com
}

impact. Seat safety refers to the ability to prevent vehicle accidents effectively and to reduce the damage of occupants to a minimum at the time of the accident [10]. Research on vehicle seat in a front and rear collision mechanism of injury to the occupant can provide theoretical technical support for the seat design, research and development. It can improve vehicle passive safety performance in a collision and have greater significance in traffic safety [11-13].

Based on a domestic car seat, a seat-occupant finite element model was established by using HyperMesh and LSDYNA simulation software to study the passenger injury characteristics during front and rear impact. The main purpose was to analyze the performance of the seat and the improvement and optimization of the structure, thus to improve dummy injury indicators to provide effective protection for occupants and also to provide a method for modern seat design and passenger protection evaluation.

\section{DUMMY-SEAT MODEL ESTABLISHMENT AND ANALYSIS}

\subsection{Model Establishment}

The CAD geometric model was imported to HyperMesh software and meshed according to engineering experience. In this model, the sheet metal parts using two-dimensional grid method were meshed by quadrilateral element and triangular element. Three-dimensional mesh was used in headrest, backrest, cushions and other special components. Belt model was the combination of one-dimensional multi-rigid-body seat belt element and two dimensional membrane elements. Model grid size was controlled at about $10 \mathrm{~mm}$. Final mesh model is shown in Fig. (1). 
a) FE model

b) FE model with dummy
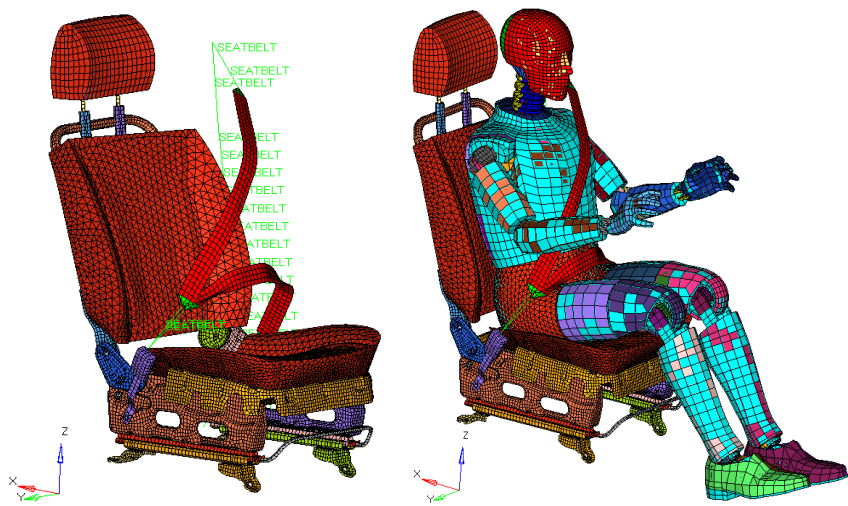

Fig. (1). FE model seat-dummy.

A total of 30954 nodes and 93421 elements were included in this model. And then, on the basis of this seat model to join Hybrid , 50\% male dummy completed the dummy-seat model as shown in Fig. (1).

\subsection{Front and Rear Impact Setup}

For front impact, the analysis was a low speed collision. In accordance with requirements of the low-speed collision, the collision speed was selected $50 \mathrm{~km} / \mathrm{h}$, at X-axis negative direction. Collision time was $150 \mathrm{~ms}$. Acceleration curve is shown in Fig. (2), which was obtained by vehicle collision test. The chest compression, chest $3 \mathrm{~ms}$ synthetic acceleration data were used as evaluation indexes.

For rear impact, the speed of rear collision was $50 \mathrm{hm} / \mathrm{h}$, in $\mathrm{X}$ direction. The remaining boundary conditions were the same as the frontal collision simulation. Seat acceleration curve is shown in Fig. (3), which was obtained by the collision test of the vehicle.

\subsection{Model Verification}

To verify the model, $\mathrm{X}$ direction acceleration curve of chest was used. The real test and simulation curves are shown in Fig. (4). Similar trend was observed in the curves with almost the same maximum time. The maximum $\mathrm{X}$ acceleration of simulation was $35.5 \mathrm{~g}$ and that for the test was $40.53 \mathrm{~g}$. The difference was below $20 \%$. The occupant

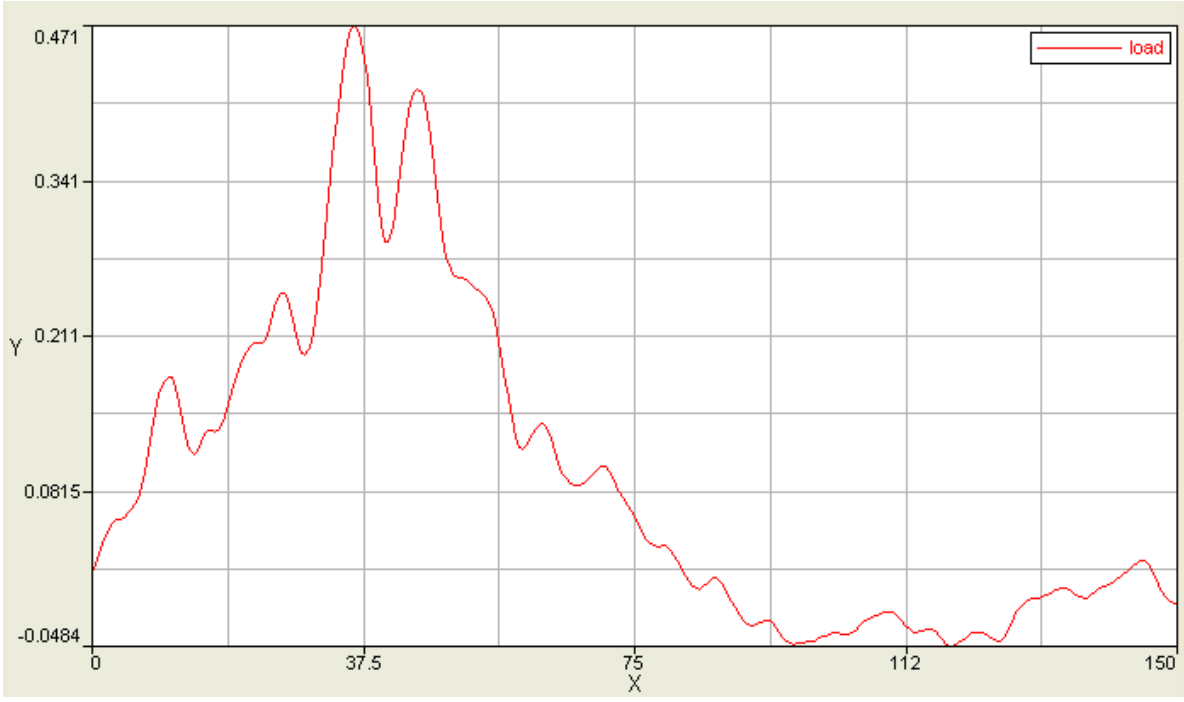

Fig. (2). Acceleration curve of front impact.

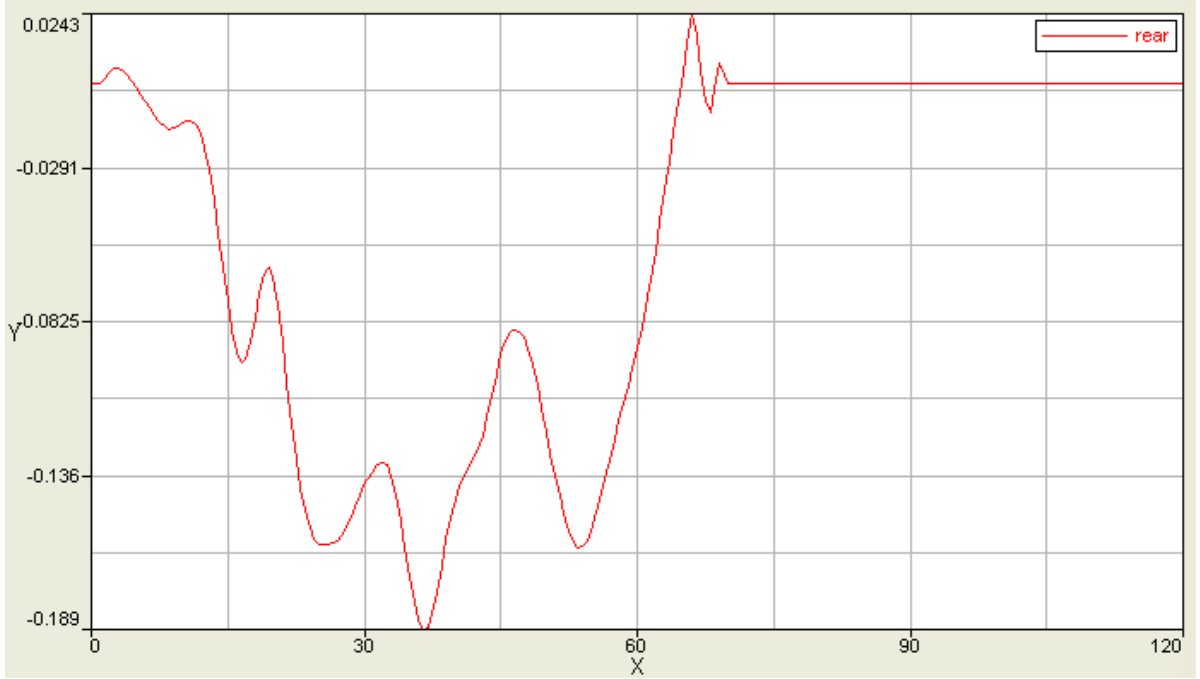

Fig. (3). Acceleration curve of rear impact. 
protection performance of simulation was valid which indicated that the model can be used for simulation [14].

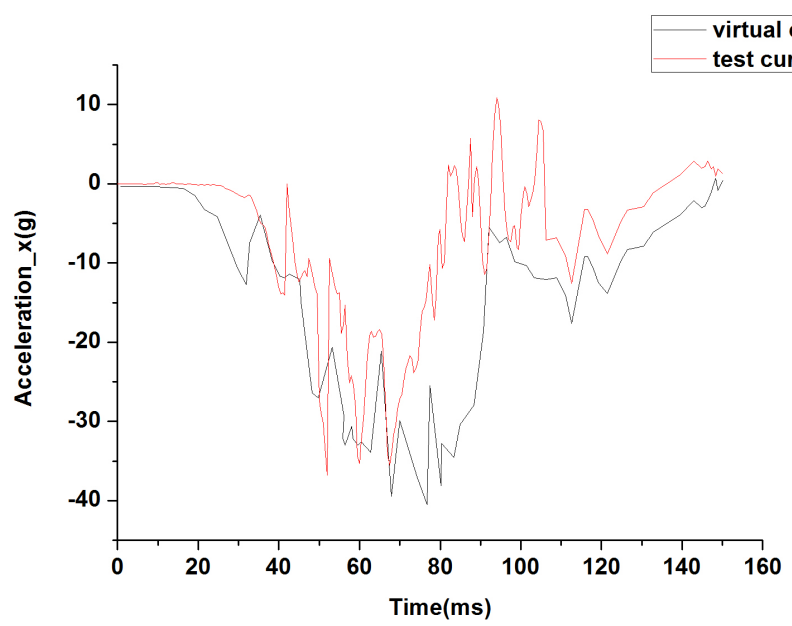

Fig. (4). Chest $X$ acceleration curves of test and simulation.

\section{OCCUPANT INJURY ANALYSIS}

\subsection{Frontal Impact}

Fig. (5) shows that the maximum amount of chest compression was $63.84 \mathrm{~mm}$ which was higher than the CNCAP requirement $(50 \mathrm{~mm})$, and the value higher than $50 \mathrm{~mm}$ period was about $50 \mathrm{~ms}$ leading to a large amount of dummy chest compression resulting in more serious injuries in chest. $3 \mathrm{~ms}$ synthesis acceleration of chest was $24.67 \mathrm{~g}$ Fig. (6), meeting CNCAP requirement. Results indicated that modification should be carried out to optimize seat for better front injury protection.

\subsection{Rear Impact}

As shown in Fig. (7), dummy neck $X$ to a maximum force FX was $881 \mathrm{~N}$. The value was greater than zero starting at around $104 \mathrm{~ms}$, and was largely changed. The neck Xforce FX was over $730 \mathrm{~N}$ (CNCAP value) and had a longer duration with more than $15 \mathrm{~ms}$. This showed that there was larger impact force acting on the dummy neck over a long period of time which could cause greater harm to the dummy neck. Optimization was needed to meet the requirement.

For $Z$-torque $\mathrm{M}_{\mathrm{Z}}(12.13 \mathrm{~N} \cdot \mathrm{m})$, the value was greater than 0 after $102 \mathrm{~ms}$ which could cause some dummy neck injury as shown in Fig. (8).

With the increase in the force of the backrest, the backrest angle was increased Fig. (9). The maximum change of the backrest angle was $22.97^{\circ}$, which could be further optimized.

\section{SEAT STRUCTURE ORTHOGONAL DESIGN OPTIMIZATION}

\subsection{Orthogonal Design Arrangement}

Based on the previous study of Chen [15], the seat structure was modified through three aspects, seat side plate, the lower bracket under cushion and back lock member, by combining the stress analysis during front and rear impact simulation, and industry engineering experience. The factors and level of each factor are shown in Table 1. And a mixed orthogonal table $\mathrm{L}_{8}\left(4 \mathrm{X} 2^{2}\right)$ is shown in Table 2.

\subsection{Orthogonal Analysis}

Based on the experimental arrangement, specific modification was carried out to establish the corresponding

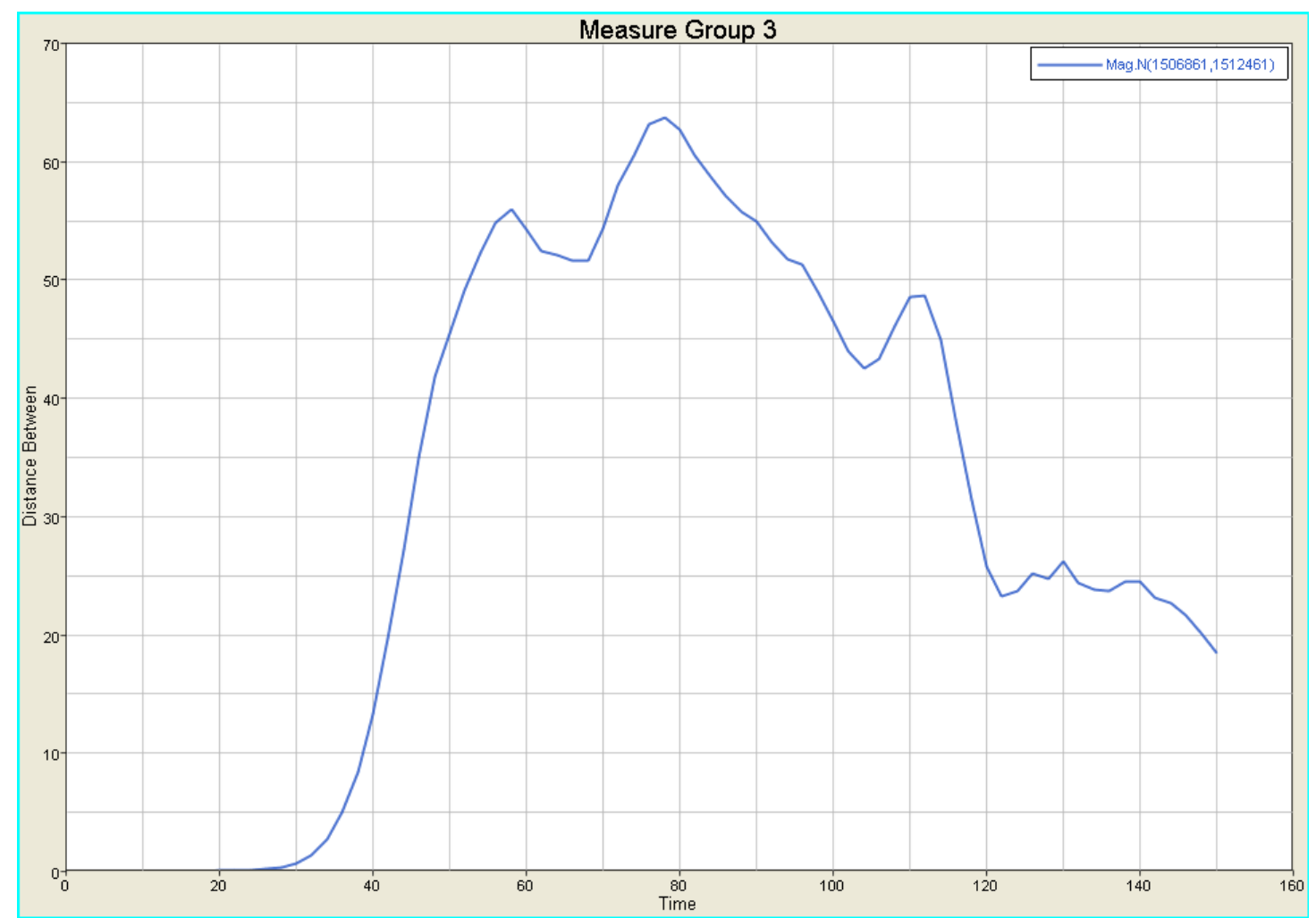

Fig. (5). Chest compression of dummy (mm). 


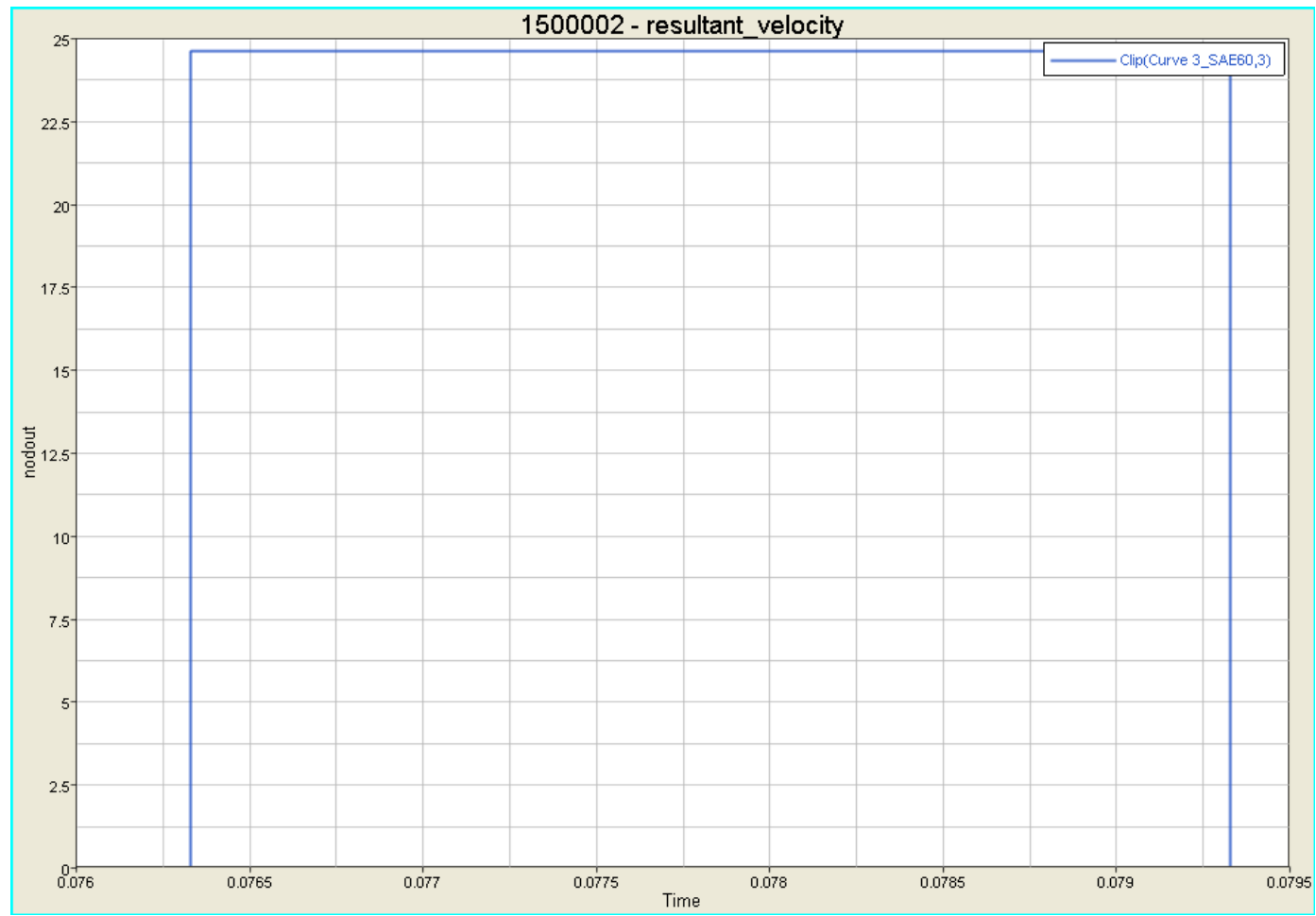

Fig. (6). $3 \mathrm{~ms}$ synthetic acceleration of chest (g).

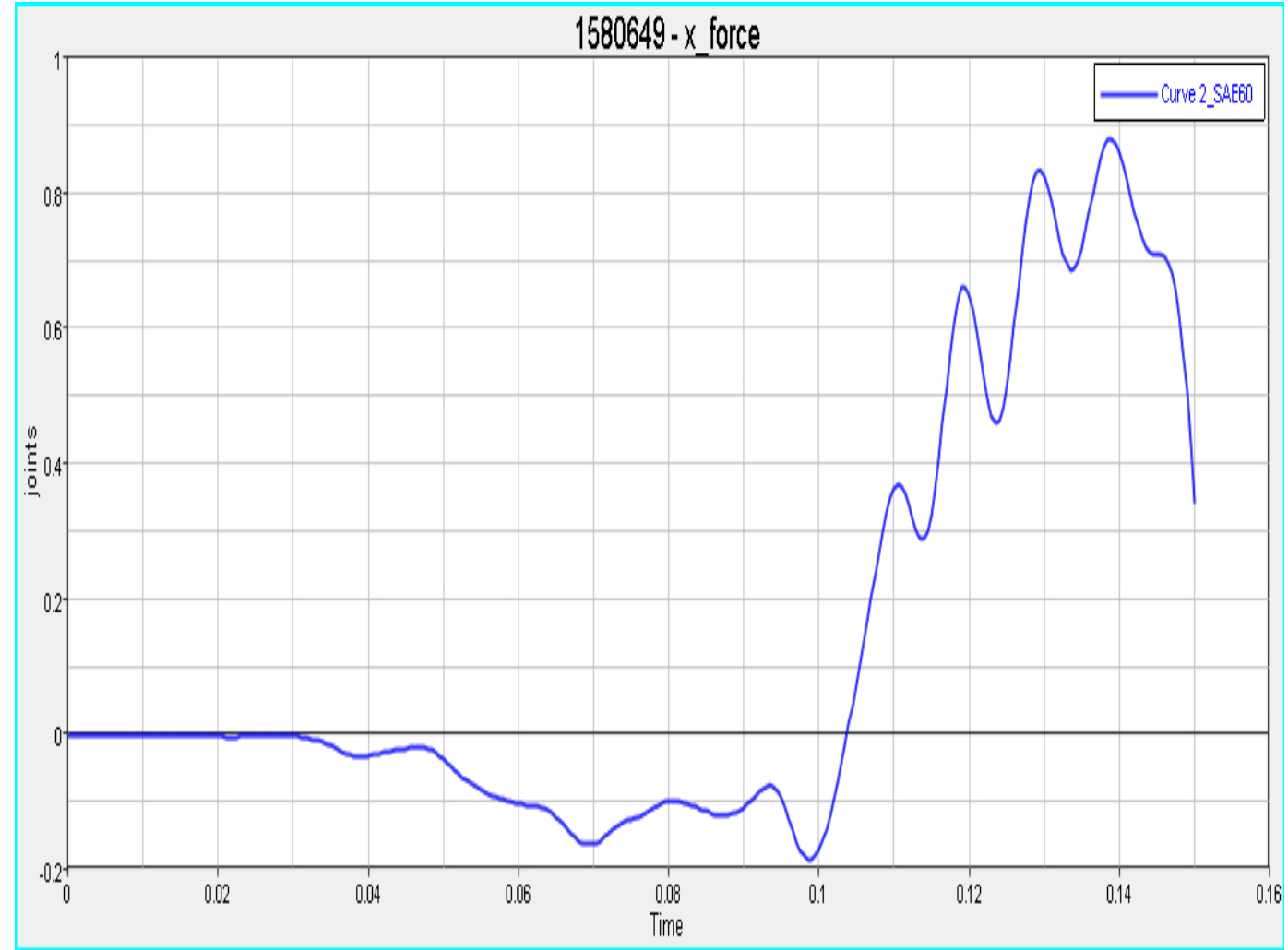

Fig. (7). Curve of X force of dummy neck (N).

model. All the modes were simulated in front and rear impact. The simulation results are shown in Table $\mathbf{3}$. Results indicated that the occupant injury was reduced after different modification.
In order to determine the primary and secondary sequence of each factor, range analysis was applied. The simulation experiment data and range $\mathrm{R}$, and the referred range $\mathrm{R}^{\prime}$ are shown in Table 4 . 


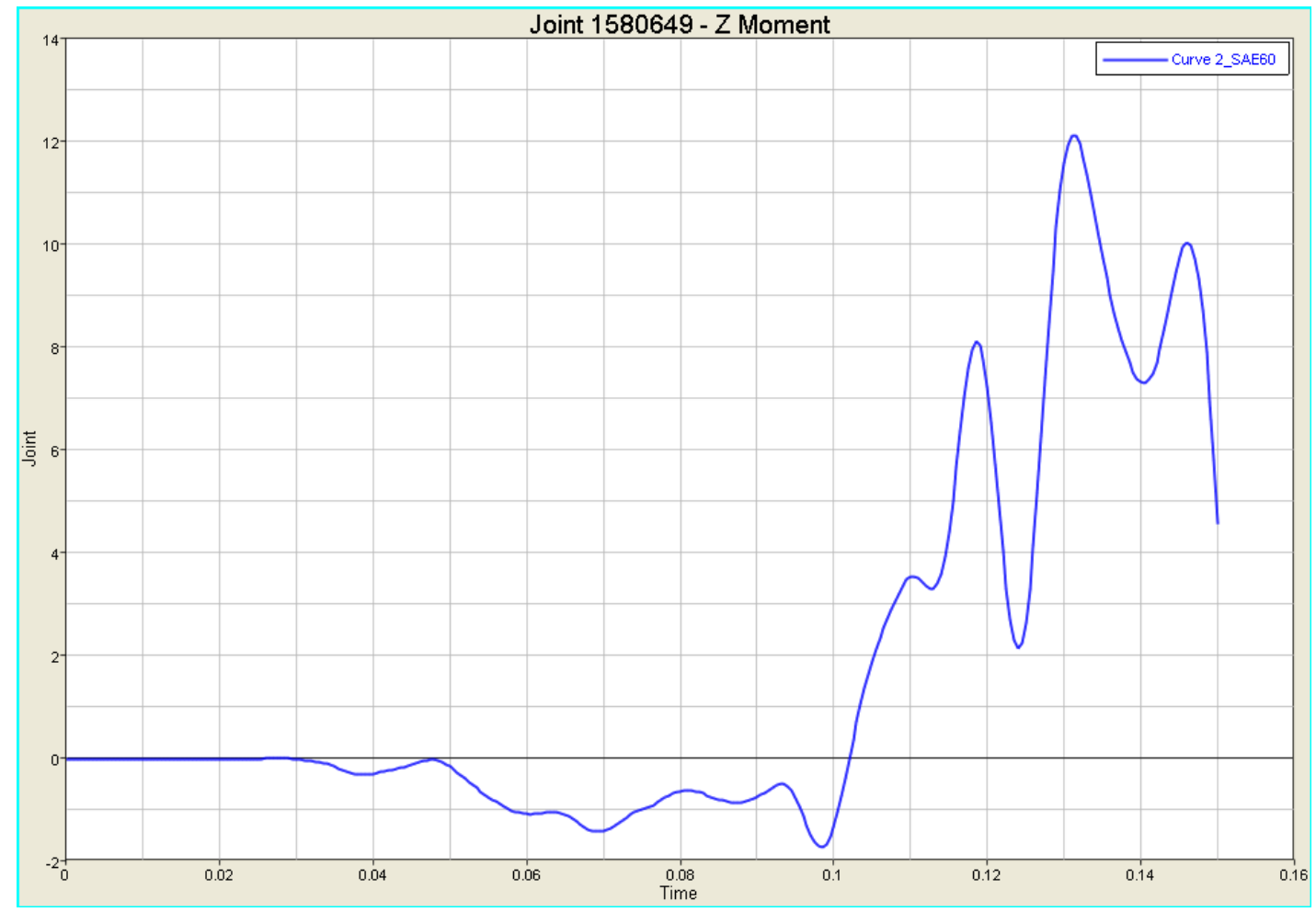

Fig. (8). Curve of $\mathrm{Z}$ moment of dummy neck $(\mathrm{N} \cdot \mathrm{m})$.

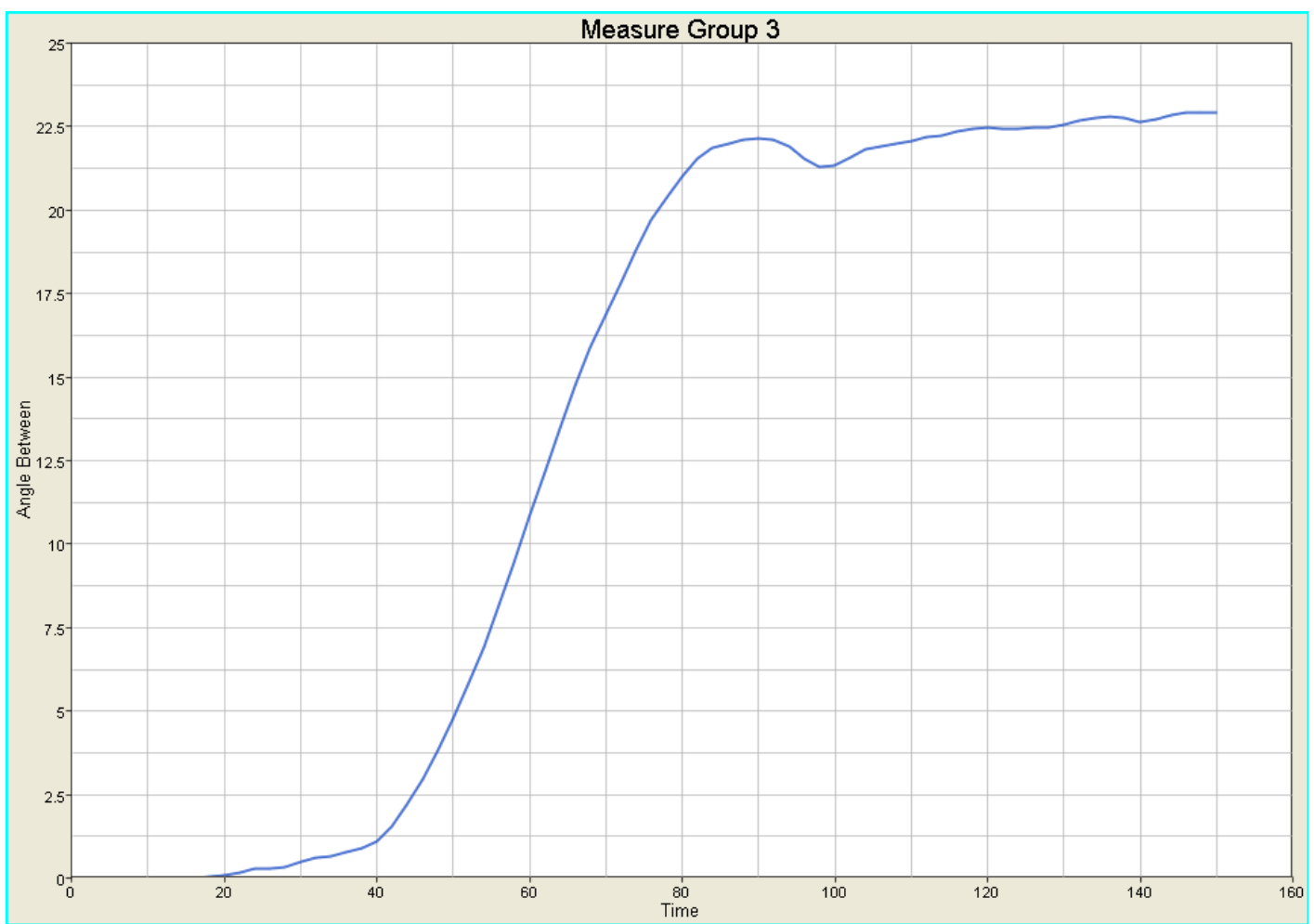

Fig. (9). Angle change of backrest $\left(^{\circ}\right)$.

For chest compression, the sequence was C-A-B, with the best combination of $\mathrm{A}_{2} \mathrm{~B}_{1} \mathrm{C}_{1}$. For $3 \mathrm{~ms}$ synthetic acceleration, the sequence was $\mathrm{B}-\mathrm{C}-\mathrm{A}$, with the best combination of $\mathrm{A}_{4} \mathrm{~B}_{2} \mathrm{C}_{2}$. It is indicated that the lower portion had relatively important effect on chest compression and $3 \mathrm{~ms}$ synthetic acceleration.
For neck $\mathrm{F}_{\mathrm{x}}$, the influence order was $\mathrm{A}-\mathrm{C}$ - $\mathrm{B}$, with the best group $\mathrm{A}_{2} \mathrm{~B}_{1} \mathrm{C}_{1}$. For Neck $\mathrm{M}_{\mathrm{Z}}$, the order was $\mathrm{A}-\mathrm{B}-\mathrm{C}$, with the best group $A_{4} B_{1} C_{1}$. It was illustrated that the back lock member had major effect on occupant neck injury.

To determine the optimized option, integrated balance method was used. According to the simulation results, 3 
Table 1. Factor and level of this orthogonal table.

\begin{tabular}{|c|c|c|c|c|c|}
\hline & Factor & Level 1 & Level 2 & Level 3 & Level 4 \\
\hline \hline A & Back lock member & $142 \mathrm{~mm}$ & $221 \mathrm{~mm}$ & $269 \mathrm{~mm}$ & Using left structure to replace right \\
\hline B & Side plate & 2 holes & no holes & & \\
\hline C & Lower bracket & Original structure & Arc transit & & \\
\hline
\end{tabular}

Table 2. Orthogonal table of L8 $\left(4 \times 2^{2}\right)$.

\begin{tabular}{|c|c|c|c|c|}
\hline Experiment Number & A & B & C & Experiment Combination \\
\hline \hline 1 & 1 & 1 & 1 & A1B1C1 \\
\hline 2 & 1 & 2 & 2 & A1B2C2 \\
\hline 3 & 2 & 1 & 1 & A2B1C2 \\
\hline 4 & 2 & 1 & 2 & A2B2C1 \\
\hline 5 & 3 & 2 & 2 & A3B2C2 \\
\hline 6 & 3 & 1 & A4B1C2 \\
\hline 7 & 4 & 2 & 1 & A4B2C1 \\
\hline 8 & 4 & 1 & 2 & 2 \\
\hline
\end{tabular}

Table 3. Simulation results.

\begin{tabular}{|c|c|c|c|c|c|}
\hline & & Chest Compression/mm & 3 ms Synthetic Acceleration/g & Neck $\mathbf{F}_{\mathbf{x}} / \mathbf{N}$ & Neck $\mathbf{M}_{\mathbf{Z}} / \mathbf{N} \cdot \mathbf{m}$ \\
\hline \hline 1 & A1B1C1 & 63.84 & 24.67 & 881 & 12.13 \\
\hline 2 & A1B2C2 & 62.99 & 22.45 & 868 & 12.35 \\
\hline 3 & A2B1C2 & 57.19 & 20.83 & 773.26 & 14.65 \\
\hline 4 & A2B2C1 & 54.34 & 21.06 & 765.05 & 16.25 \\
\hline 5 & A3B1C1 & 50.52 & 23.56 & 848 & 10.84 \\
\hline 6 & A3B2C2 & 64.00 & 19.65 & 789.49 & 16.15 \\
\hline 7 & A4B1C2 & 64.39 & 20.76 & 767.25 & 11.08 \\
\hline 8 & A4B2C1 & 61.28 & 20.24 & 1.21 \\
\hline
\end{tabular}

factors had different sequence on the selected occupant injury index. Factor $A$ had larger effect on neck $F_{x}$ and $M_{z}$. $\mathrm{A}_{4}$ had the best overall performance. Factor $\mathrm{B}$ had larger effect on $3 \mathrm{~ms}$ synthetic acceleration, and the best option was $\mathrm{B}_{2}$. Factor $\mathrm{C}$ had larger effect on chest compression, with the best option $\mathrm{C}_{2}$. Therefore, the optimized solution was $\mathrm{A}_{4} \mathrm{~B}_{2} \mathrm{C}_{2}$

\subsection{Occupant Protection Performance of Optimized Model}

On the basis of the improvement structure, the optimized seat finite element model was established. Improved model analysis was carried out again in LS-DYNA, and compared with the simulation results of the original model. Chest compression, 3ms resultant acceleration, neck X-force, Zmoment and seat back angle were compared before and after optimization, as listed in Table $\mathbf{5}$.
As shown in Table 4, the dummy injury indicators decreased obviously. Among them, the backrest angle, chest compression and $3 \mathrm{~ms}$ synthetic acceleration decreased $17.21 \%$ and $21.16 \%$, respectively. This was due to the increase in optimized sides' strength, so that the seat could withstand a greater impact in front collision. Due to the modification on back lock member and center hinge, the seat can reduce force and torque on neck. The dummy neck $F_{X}$ decreased $15.44 \%, \mathrm{M}_{\mathrm{Z}}$ value decreased $3.13 \%$, and its angle variation also decreased. The dummy rebound decreased when impacted by an external force. Results illustrate that the optimized structure can improve occupant protection during front and rear impact.

\section{CONCLUSION}

(1) Dummy-seat model was established by HyperMesh and LS-DYNA software. Analysis was conducted to determine the performance of seat in dummy protection during front and rear impact. Results 
Table 4. Analysis of simulation results.

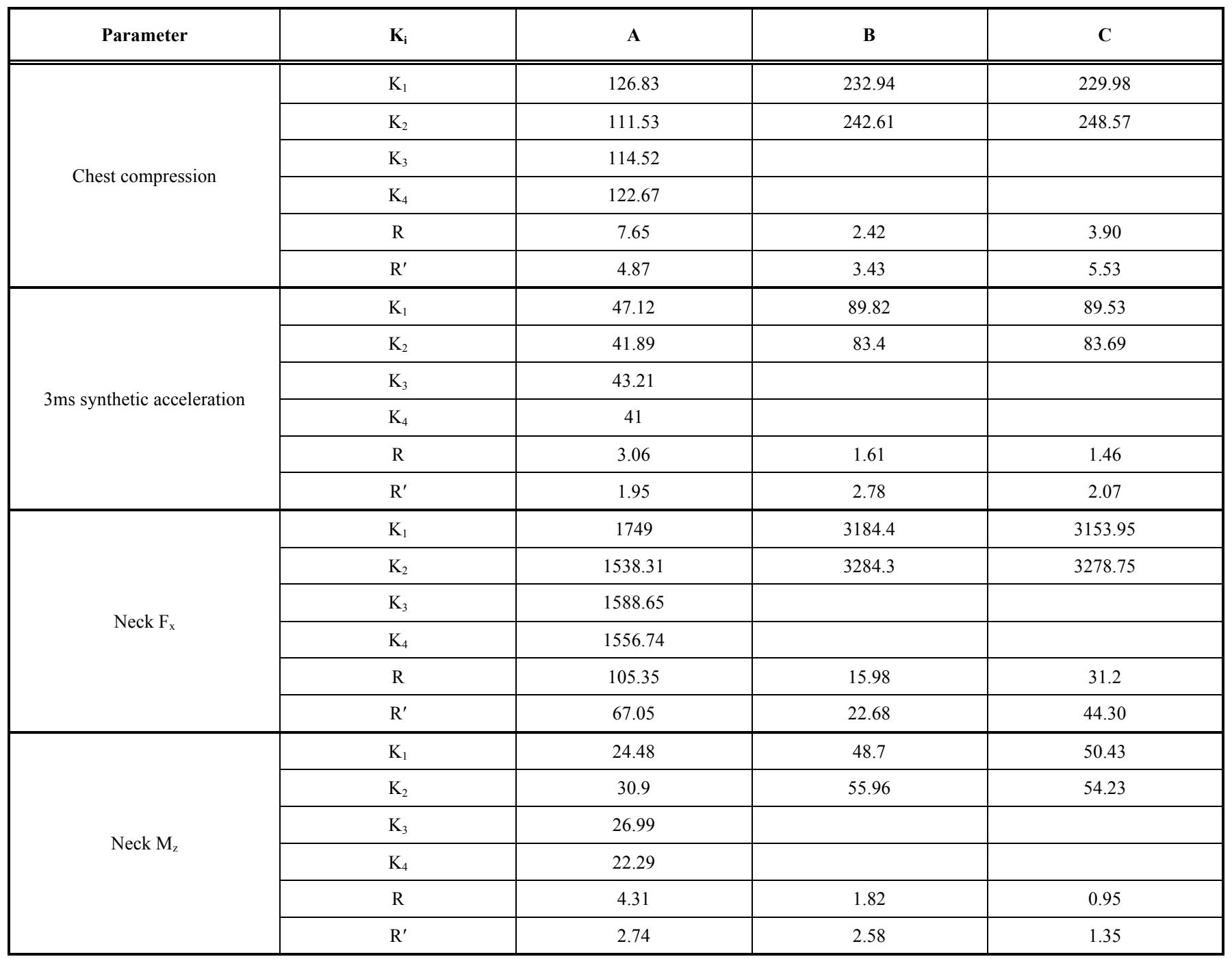

Table 5. Comparison before and after optimization.

\begin{tabular}{|c|c|c|c|c|}
\hline Index & Original & Optimized & Difference & Rate of Change \\
\hline \hline Chest compression/mm & 63.84 & 52.85 & 10.99 & $17.21 \%$ \\
\hline $3 \mathrm{~ms}$ synthetic acceleration/g & $24.67 \mathrm{~g}$ & $19.45 \mathrm{~g}$ & 5.22 & $21.16 \%$ \\
\hline $\mathrm{F}_{\mathrm{X}} / \mathrm{N}$ & 881 & 745 & 136 & $15.44 \%$ \\
\hline $\mathrm{M}_{\mathrm{Z}} / \mathrm{N} \cdot \mathrm{m}$ & 12.13 & 11.75 & 0.38 & $3.13 \%$ \\
\hline Backrest angle/ & 22.97 & 12.38 & 10.59 & $46.10 \%$ \\
\hline
\end{tabular}

indicated that the structure needed modification to ensure passenger protection.

(2) The seat structure was modified through orthogonal experiment design and the best optimization option was $\mathrm{A}_{4} \mathrm{~B}_{2} \mathrm{C}_{2}$.

(3) It was indicated that the optimized structure can improve passenger protection. Chest compression reduced $17.21 \%, 3 \mathrm{~ms}$ resultant acceleration reduced $21.16 \%$, dummy neck $\mathrm{F}_{\mathrm{X}}$ decreased $15.44 \%, \mathrm{M}_{\mathrm{Z}}$ value decreased $3.13 \%$, and backrest angle decreased $46.1 \%$.

\section{CONFLICT OF INTEREST}

The authors confirm that this article content has no conflict of interest.

\section{ACKNOWLEDGEMENTS}

The research was funded by the 12nd Five-year Support Program in Shanghai University of Engineering Science 
(nhky-2012-09), and the Shanghai Education Committee Innovation Program (13YZ109).

\section{REFERENCES}

[1] China Communications and Transportation Association. Chinese Transportation Yearbook. People's Communications Press: Beijing, China, 2012, pp. 83-115.

[2] H. Chen, "Structural design and finite element simulation of automobile driver seat", M.S. thesis, Northeastern University, Shenyang, China, 2010.

[3] Q.H. Li, J.P. Li, and S.H. Li, "Finite element analysis and test study about sled impact test of automobile seat", Automobile Technology, vol. 5, pp. 30-34, 2007.

[4] J.X. Jin, "Research on headrest and wield stripes performance and improvement of a car seat", M.S. thesis, Jilin University, Changchun, China, 2011.

[5] H.Y. Yang, "Prevent and stripes for the optimization design of the safety seat research", M.S. thesis, Hunan University, Changsha, China, 2012.

[6] N. Bourdet and R. Willinger, "Human body-car seat coupling under rear impact", In: Infats Proceedings of the, International Forum of Automotive Traffic Safety, 2005.

[7] M. Sawada, and J. Hasegawa, "Development of New Whiplash Prevention Seat", In: $19^{\text {th }}$ International Technical Conference on the Enhanced Safety of Vehicles, 2005.
[8] J. Chen, "The research of passenger's injury and improvement during the rear-end collision", M.S. thesis, Wuhan University of Science and Technology, Wuhan, China, 2013.

[9] H.B. Wang, "Analysis of strength and stiffness for automotive seat on front crash", M.S. thesis, Hunan University, Changsha, China, 2012

[10] D.F. Wang, "A study on the impact safety of commercial vehicle cab and its improvement", Automotive Engineering, vol.1, pp. 3436, 2011.

[11] H.Q. Long, J.H. Chen, and Y.X. Wu, "Application of CAE in development of automotive seat frame", Computer Aided Engineering, vol. 20, pp. 112-115, 2011.

[12] M.K. Shin, and K.J. Park, "Occupant analysis and seat design to reduce neck injury from rear end impact", International Journal of Crashworthiness, vol. 8, pp. 573-581, 2003.

[13] D.J. Chen, D.C. Fu, and H.H. Wang, "Lightweight design of car seats", Mechanical Science and Technology for Aerospace Engineering, vol. 30, pp. 26-32, 2011.

[14] L.J. Hu, "Study on automobile side impact and safety for the occupant protection", M.S. thesis, Liaoning Institution of Technology, Jinzhou, China, 2007.

[15] H.N. Chen, H. Chen, and L.J. Wang, "Analysis of vehicle seat and research on structure optimization in front and rear impact", World Journal of Engineering \& Technology, vol. 2, pp. 78-85, 2014.

(C) Yang et al.; Licensee Bentham Open.

This is an open access article licensed under the terms of the Creative Commons Attribution Non-Commercial License (http://creativecommons.org/licenses/by-nc/4.0/) which permits unrestricted, non-commercial use, distribution and reproduction in any medium, provided the work is properly cited. 